\title{
A APLICAÇÃO DOS MÉTODOS RESTAURATIVOS NA RESOLUÇÃO DOS CONFLITOS MIGRATÓRIOS: DO COMBATE À INVISIBILIDADE SOCIAL AO RECONHECIMENTO DOS DIREITOS HUMANOS DOS REFUGIADOS E MIGRANTES
}

\author{
THE APPLICATION OF RESTORATIVE METHODS IN THE RESOLUTION OF MIGRATORY \\ CONFLICTS: FROM FIGHTING SOCIAL INVISIBILITY TO RECOGNIZING HUMAN RIGHTS OF \\ REFUGEES AND MIGRANTS
}

Luciano de Oliveira Souza Tourinho ${ }^{1}$ Pedro Garrido Rodríguez ${ }^{2}$ Ana Paula da Silva Sotero ${ }^{3}$

\begin{abstract}
Resumo: As crises migratórias contemporâneas colocaram como destaque da preocupação internacional, a necessidade de cooperação dos países para a ajuda humanitária de acolhimento dos migrantes e refugiados, a fim de garantir a esses indivíduos as condições essenciais à vida digna, com respeito aos direitos humanos. No entanto, diante do contexto de fragilidade das relações sociais e da desconstituição dos vínculos comunitários contemporâneos, surgiram conflitos migratórios decorrentes da percepção distorcida que se faz dos migrantes e refugiados, que são subjugados e invisibilizados, dentro do seio social, como inimigos. Desse modo, a presente pesquisa propõe um debate crítico sobre a atuação brasileira dentro do sistema de proteção internacional dos direitos humanos, com o intuito de desmistificar as raízes que norteiam os preconceitos contra o estrangeiro, que são, simbolicamente, marginalizados dentro da sociedade brasileira. Nesse desiderato, o estudo buscará analisar a possibilidade de aplicação dos métodos restaurativos, por meio da política pública criada no âmbito do Poder Judiciário com a publicação da Resolução n ${ }^{\circ}$ 225/2016, pelo Conselho Nacional de Justiça, como instrumentos de pacificação social para os conflitos migratórios, por meio da desconstrução dos estigmas contra os refugiados e migrantes, com vistas a garantir a edificação de bases sólidas para a efetividade dos direitos humanos a todos os indivíduos. Tal estudo se fundamentará no uso de pesquisa exploratória, com procedimentos bibliográficos e documentais acerca da Justiça Restaurativa e seus métodos de aplicação.
\end{abstract}

Palavras-chave: Conflitos migratórios. Direitos Humanos. Invisibilização social. Justiça restaurativa. Pacificação social.

Abstract: The contemporary migratory crises have highlighted the need for countries to cooperate in providing humanitarian aid for the reception of migrants and refugees, in order to guarantee them the essential conditions for a dignified life with respect to human rights. However, in the context of fragility of social relations and the deconstitution of contemporary community ties, migratory conflicts have arisen as a result of the distorted perception of migrants and refugees, who are subjugated and invisible within the social sphere as enemies. In this way, the present research proposes a critical debate about the Brazilian performance within the system of international protection of human rights, in order to demystify the roots that guide the prejudices against the foreigner, who are symbolically marginalized within Brazilian society. In this regard, the study will seek to analyze the possibility of applying restorative methods, through public policy created within the scope of the

\footnotetext{
Pós-Doutor em Direitos Humanos (Direitos Sociais) pela Universidad de Salamanca; Doutor em Direito Público - Direito Penal pela Universidade Federal da Bahia; Professor Adjunto de Direito Penal e Direito Processual Penal na Universidade Estadual do Sudoeste da Bahia; https://orcid.org/0000-0002-0442-4658; luciano.tourinho.jus@gmail.com

2 Doutor em Direito em Passado e Presente dos Direitos Humanos pela Universidade de Salamanca; Graduado em Humanidades pela Universidade de Salamanca; Pesquisador do Seminário Internacional de História Contemporânea dos Direitos Humanos da Universidade de Salamanca; https://orcid.org/0000-0002-4949-4692; pegarro@usal.es

Especialista em Criminologia pela Faculdade de Paraíso do Norte; mestranda em Direito pela Universidade Federal da Bahia; Membro do grupo de pesquisa Culpabilidade, Vulnerabilidade e Seletividade Penal; Rua E, n. 79, Caminho da Universidade, 45029-264, Candeias, Vitória da Conquista, Bahia, Brasil; https://orcid.org/0000-0002-3426-0666; anapaula_sotero@ hotmail.com
} 
Judiciary with the publication of Resolution $\mathrm{n}^{\circ}$ 225/2016, by the National Council of Justice, as instruments of social pacification for migratory conflicts, by deconstructing stigmas against refugees and migrants, with a view to guaranteeing the building of solid bases for the effectiveness of human rights for all individuals. Such a study will be based on the use of exploratory research, with bibliographic and documentary procedures on Restorative Justice and its methods of application.

Keywords: Migratory conflicts. Human rights. Social invisibility. Restorative justice. Social pacification.

Recebido em 17 de julho de 2019 Avaliado em 24 de abril de 2020 (AVALIADOR A) Avaliado em 7 de setembro de 2020 (AVALIADOR B)

Aceito em 2 de outubro de 2020

\section{Introdução}

O cenário mundial contemporâneo denota a preocupação internacional com os deslocamentos dos povos devidos às crises políticas, sociais e econômicas vivenciadas nos seus países de origem. Povos que são expostos à miserabilidade e à constante instabilidade de sobrevivência buscam refúgio em outras nações, como meio de garantir o mínimo existencial.

Por essas razões a preocupação internacional trilha no sentido de reconhecer a necessidade de proteção dos direitos humanos desses sujeitos, a fim de que outras nações estejam abertas para a cooperação de acolhimento desses povos. Respaldados pelo caráter transnacional, os direitos essenciais à vida são colocados como valores supremos a serem obedecidos pelas ordens jurídicas dos países, que devem buscar abrigar e recepcionar os indivíduos em uma missão de humanidade.

No entanto, o que se percebe é que os migrantes e refugiados, que já foram oprimidos no seu país local, passam a ser ameaçados nos países receptores, em razão dos conflitos migratórios com os povos nacionais. $\bigcirc$ medo e a hostilidade com o estrangeiro, sustentados pelos preconceitos xenófobos, que permeiam, simbolicamente, a sociedade, fazem com que a permanência desses indivíduos seja uma nova forma de subjugação e supressão de direitos.

Nota-se que os conflitos e as tensões entre os estrangeiros e os brasileiros são disputas marcadas pela opressão e invisibilização dos refugiados e migrantes, que são colocados à margem da sociedade e vistos como inimigos da nação. Desse modo, tendo por objetivo a conscientização da população para o respeito aos direitos humanos aos estrangeiros, a Justiça Restaurativa ${ }^{4}$ surge como um método alternativo de solução dos conflitos, com vistas à pacificação social.

Revestidos por ideais de justiça, do diálogo e do respeito ao próximo, os modelos restaurativos se apresentam como um processo de reformulação da própria concepção que se tem do migrante e refugiado dentro do país. Abre-se a possibilidade para a erradicação das mazelas sociais e para a efetiva justiça social, garantindo o cumprimento dos direitos humanos a todos os indivíduos.

\footnotetext{
${ }^{4}$ Justiça Restaurativa - Política Pública Instituída pelo Conselho Nacional de Justiça com a Resolução № 225/2016, cuja ementa se lê: "Dispõe sobre a Política Nacional de Justiça Restaurativa no âmbito do Poder Judiciário e dá outras providências."
} 
Nesse prisma, a pesquisa proposta tem por objetivo a análise da aplicabilidade dos métodos restaurativos nos conflitos presentes nos fenômenos migratórios, como instrumentos de pacificação social e restabelecimento da igualdade de direitos aos indivíduos. Com vistas à desconstrução dos discursos de ódio ao imigrante, a Justiça Restaurativa dará a oportunidade do diálogo, trazendo a reflexão e a sensibilização dos residentes locais para se colocarem na posição dos estrangeiros.

Para alcançarmos os objetivos delineados na presente proposta, utilizamo-nos de uma orientação metodológica exploratória, com estudo documental dos refugiados que residem no país, a partir de informações relativas às influências aos movimentos migratórios recentes, bem como a construção discursiva que recai sobre esse fenômeno e a efetividade de direitos sociais. Ademais, realizamos uma pesquisa dos procedimentos técnicos bibliográficos e documentais acerca da Justiça Restaurativa e seus métodos de aplicação, fazendo uma abordagem histórica e conceitual, com fundamento nos métodos dialético e fenomenológico.

Nessa linha de intelecção, torna-se necessário compreender o fenômeno mencionado, à luz da Justiça Restaurativa, no sentido de tocar a origem e causa dos conflitos culturais entre imigrantes e locais, possibilitando o amadurecimento pessoal da população do país de origem acerca da presença dos refugiados e imigrantes, com vistas a viabilizar a realização de direitos que garantem a existência digna ao sujeito refugiado ou migrante.

\section{As crises migratórias: uma incursão histórica sobre as origens e consequências do êxodo humanitário nas realidades democráticas contemporâneas}

O deslocamento de pessoas entre territórios é um processo complexo e multifacetário, que envolve causas e motivações variadas ao longo do desenvolvimento das sociedades históricas. Nesse sentido, observa-se que os fluxos migratórios possuem desdobramentos sociais, que revelam as transformações políticas, culturais e econômicas dos países. Sob esse égide, Elie (2014) estabelece que os estudos dos fluxos migratórios perpassam pela consideração das transformações das próprias realidades sociais da contemporaneidade.

Destarte, nota-se que os deslocamentos forçados ou voluntários são revestidos de potencialidades casuísticas, que refletem o contexto histórico de cada geração histórica social. Dentro dessa linha de intelecção, explica Rodríguez (2012, p. 27) que

son muchas y diversas las definiciones propuestas para describir los movimientos migratorios, existentes desde siempre. El asunto ha sido tratado en numerosas ocasiones y sin embargo no podemos afirmar que exista un concepto totalmente clarificador $y$ generalmente aceptado entre los estudiosos de la material.

Por esse aspecto, faz-se necessário analisar as diferenças conceituais existentes entre as migrações forçadas e voluntárias, a fim de compreender os contextos históricos que estão relacionados 
a esses dois tipos de deslocamento humano e quais as disposições internacionais que os diferentes povos migrantes estão inseridos dentro do contexto de proteção global dos direitos dos povos.

Segundo a Organização Internacional para as Migrações - OIM (2009), as migrações são divididas em duas categorias básicas: as migrações voluntárias e as migrações forçadas. Na esteira dessas categorias, o conceito de migrante é formado pela consideração do sujeito que se desloca do seu país de origem. No entanto, tal divisão é criticada por parte da doutrina, tendo em vista que a palavra migração pressupõe, por critério lógico, a ação livre e voluntária do ser humano, não sendo possível relacionar a sua vontade com qualquer evento externo que o tenha influenciado.

Em consonância com esse entendimento doutrinário, Murillo (2008, p. 22) conceitua a migração como "o deslocamento de pessoas de forma voluntária e com caráter permanente ou temporário, com o intuito de buscar melhores condições de vida." Nessa ilação, percebe-se que qualquer causa que leve ao deslocamento forçado de povos, não se enquadra no conceito de migração, por destituir a liberdade de conduta do indivíduo. Nessa mesma linha de intelecção, observamos que:

Migração pode ser definida como movimento de pessoas que se estabelecem temporária ou permanentemente, sendo internas quando dentro do próprio país ou internacionais quando de um país para outro. As causas para circulação de pessoas são variadas, podendo decorrer de desastres naturais, falta de alternativas econômicas ou condições de sobrevivência. Nestes casos, migrar para outro país se torna uma alternativa para recomeçar a vida, através da busca de oportunidades de trabalho, satisfação de necessidades básicas, como saúde, educação e segurança alimentar. (REZEK, 2016, p. 326).

Em atenção a esse entendimento, Rodríguez (2014) ensina que o perfil das migrações é demasiadamente multifacetado e, por isso, sempre haverá, no campo doutrinário, essa divergência conceitual, tendo em vista que os fluxos migratórios, apesar de inerentes às sociedades históricas, são marcados pela complexidade de causas. À guisa dessas informações, o referido autor assevera que

su estudio requiere, más que una teoría generalista-con el peligroso riesgo de caer en el reduccionismo- un corpus de perspectivas interdisciplinares que ayuden a comprender las dimensiones específicas de las migraciones y proporcionen hipótesis coherentes verificables de manera empírica. (RODRÍGUEZ, 2012, p. 39-40).

Por essa mudança de perspectiva, ao se analisar a realidade prática, percebe-se que o deslocamento forçado passou a ser classificado como uma subdivisão dos povos migrantes, que se dissociam por não apresentarem a característica de voluntariedade e são marcados pela influência de eventos externos, que obrigam o ser humano a buscar novos locais para sobrevivência. Portanto, segundo Purdin e McGinn (2010), os refúgios são formas de deslocamento que possuem causas multifacetárias, mas que perpassam o liame histórico de conflitos sociais, econômicos e políticos no país de origem. 
Dentro desse contexto, Andrade (2001) assevera que a história dos refugiados está intrinsecamente relacionada às lutas humanas, que colocaram povos em situação de completa vulnerabilidade social. Marcados pela disputa territorial, os conflitos resultaram na dizimação de povos e na perseguição de grupos minoritários, com o intuito de subjugação e imposição do poder da violência. Neste diapasão, o refúgio se apresenta como a busca de uma nova perspectiva de vida e sobrevivência em países vizinhos.

Quando se analisa a grave crise humanitária decorrente das disputas territoriais nos países em crise política, social e/ou econômica, percebe-se que há a supressão dos direitos humanos, em que os migrantes são expostos a situações de miserabilidade e vulnerabilidade social. Nesse sentido, o refúgio se apresenta não apenas como um novo local de moradia, mas também como a possibilidade de garantia dos direitos essenciais à sobrevivência, resgatando a humanidade que foi constantemente violada em seu país de origem, a fim de alcançar à dignidade. Vejamos:

Os refugiados são aqueles que não podem contar com a proteção de seu Estado de origem e sofrem perseguições de raça, nacionalidade, religião, por suas opiniões políticas e ainda, são vítimas de grave violação de direitos humanos. São vítimas de crises territoriais, que fazem questionar até mesmo sua condição enquanto cidadão e ser dotado de dignidade humana. Quando a opressão do ser humano se sobressai aos direitos fundamentais, o refúgio acaba sendo a última esperança de uma vida melhor. (PIOVESAN, 2016a, p. 469).

Destarte, cumpre destacar que dentro da classificação dos deslocamentos forçados ainda temos a perspectiva internacional dos apátridas, que, segundo Simeon (2013, p. 85), "refere-se aos indivíduos que não são cidadãos de qualquer Estado, não sendo titular de nacionalidade que o identifique." Dentro dessa perspectiva, tal condição revela o mais alto estágio de invisibilidade social, provocado pela discriminação e supressão dos direitos fundamentais à vida. Os apátridas são destituídos de garantias de proteção humana e são consequências das assimetrias das relações planetárias, que os impedem de se identificar como povo, pertencente a um território.

A partir dessas considerações, percebe-se que os fluxos migratórios carregam consigo o arcabouço histórico dos seus países de origem, que reclamam à cooperação internacional dos países, a fim de se garantir o respeito aos direitos humanos a todos os indivíduos, sem distinção de sua nacionalidade. Dentro desse viés, a construção teórica buscará desmistificar os processos dos fluxos migratórios ocorridos no Brasil, a fim de verificar os instrumentos de proteção nacional de abrigo dos refugiados e migrantes dentro do país, que tem sido considerado como território de predileção para rota de fuga dos estrangeiros vizinhos.

Quando se analisa a conjuntura brasileira, segundo Mazzuoli (2015), nota-se que a escolha por um país latino-americano está relacionada às reais possibilidades de sobrevivência e acesso à moradia. O referido autor revela que, durante todo o processo histórico dos fluxos migratórios, dentro da América Latina, percebe-se que, mesmo com as dificuldades econômicas dos países, as formas de 
colonização e os processos de formação dos países latino-americanos revelaram um sistema multiportas de alocação e abrigo dos migrantes, a partir da adesão aos tratados internacionais de proteção aos direitos humanos dos estrangeiros, bem como a facilidade de acesso ao território local. Vejamos:

O número de migrantes da região latino-americana aumentou de 21 milhões de pessoas, em 2000, para quase 25 milhões, em 2005 , somando $13 \%$ do total mundial, sendo que a maioria da população migrante presente na região é oriunda da própria América Latina (58,7\%), de acordo com a Comissão Econômica para América Latina e Caribe (CEPAL). Entre as razões indicadas para o crescimento da emigração intra- regional, estão presentes a continuidade cultural, as raízes históricas comuns e a diminuição de emigração ultramar. A Organização Internacional para Migrações (OIM) calcula que de 1997 a agosto de 2002, 1,2 milhões de Colombianos tenham migrado para outros países, principalmente para o Panamá, Venezuela e Equador. (CORREIA, 2008, p. 489).

Segundo Klein (2000), os fluxos migratórios na América Latina foram intensificados durante o século XX, tendo como principal elemento propulsor da migração o fim da escravidão nos países colonizados pelos europeus. A ruptura com o sistema escravagista abriu espaço para o crescimento econômico pautado na mão de obra qualificada e livre. No entanto, conforme salienta Rapoport (2000), a ausência de qualificação dos escravos libertos fez com que o cenário trabalhista fosse dominado pelos imigrantes, que vinham aos países em busca de novas condições de vida.

Dentro do cenário brasileiro, Lanza, Santos e Rodrigues (2016) afirmam que a expansão da economia agrícola, junto com a estrutura das ferrovias foram os elementos de aumento populacional estrangeiro, que passou a trabalhar nas lavouras e nas construções das estradas de ferro. Após esse período, a formação do período industrial que foi se consolidando no país, de maneira paulatina, também foi marcada pela presença dos imigrantes de mão de obra qualificada.

Nesse contexto, conforme explica Sanchez-Alonso (2007), os fluxos migratórios decorrentes da busca de emprego no país foi um processo marcado pelo livre convencimento dos povos que para aqui vieram se instalar. Sendo assim, tratou-se de um processo de deslocamento voluntário. Com o período de Guerra Mundial, vivenciado no período do final do século XX, as migrações passaram a ser motivadas como refúgio do retrocesso de direitos humanos que a Europa vivenciava.

Na perspectiva de Devoto (2007), o cenário de guerra mundial fez com que a América Latina surgisse como uma válvula de escape das consequências desastrosas da violência e dizimação de povos. Ademais, o processo de partilha do continente africano e as constantes disputas étnicoraciais levaram a intensificação do fluxo migratório, tendo países como Brasil e Argentina como refúgio humanitário. Vejamos:

As guerras étnico-raciais que assolaram os povos africanos, a disputa de terras africanas pelos europeus e a completa dizimação da cultura africana no período de colonização e industrial levou e leva os povos africanos a se deslocarem para a América-Latina, em especial o Brasil. Eles analisam o país como uma fonte de riqueza e de seguridade maior do que o seu país de origem, além da acessibilidade da linguagem e da forma de entrada no país. Essa situação se tornou como questão 
relevante de refúgios no país no período do século XX e inicio do século XXI. (HORA, 2010, p. 322).

$\mathrm{Na}$ conjuntura contemporânea, os fluxos migratórios têm se intensificado devido às crises sociais, políticas e econômicas dos países de origem, que relativizam os direitos humanos nas disputas de poder e tensões locais. Segundo o Alto Comissariado das Nações Unidas (2017), o intenso número de refugiados que adentram o Brasil "são resultados dos conflitos políticos e econômicos que vivenciam no país de origem, a exemplo da Venezuela e Colômbia e das crises humanitárias que passam a Síria, Angola e Congo."

Em análise pormenorizada da situação vivenciada pela Síria, Angola e Congo percebese que estes países enfrentam verdadeiras crises humanitárias, que, apesar de apresentarem causas de conflitos distintos, estão em consonância no sentido de não apresentarem condições dignas de sobrevivência para os seres humanos. Em atenção à realidade da Síria, a partir das lições de Toaldo (2015, p. 33) nota-se que "a onda de repressão religiosa e a liderança de grupos extremistas são a mola propulsora para o deslocamento forçado dos povos do Oriente Médio. Eles clamam por direitos básicos, pelo direito de sobreviver e garantir uma vida digna."

Já a realidade da Angola e da República do Congo evidenciam que os fluxos migratórios são intensos em razão da proximidade com a língua brasileira. Na perspectiva de Silva (2013, p. 28) "os povos refugiados notam o Brasil como o país ideal, com mais oportunidades de emprego e vida do que os outros países latino-americanos." Ademais, os dados recentes do Alto Comissariado das Nações Unidas para os Refugiados (ACNUR) (2018) revelam que estes países são os que se apresentam com o maior número de refugiados em solo brasileiro.

Por outro lado, a situação política e econômica da Venezuela tem levado a intensificação do fluxo migratório para o país como refúgio. Marcada por líderes radicais, a Venezuela tem passado por um processo de transformação política, social e econômica. Conforme salienta Obregón (2018), o governo de Nicolás Maduro representa a instauração de uma ordem social instável, marcada por decisões antidemocráticas e extremistas de solapamento dos direitos humanos.

Em meio ao caos político, o país vivencia uma grave crise econômica, que tem levado a oposição a se rebelar contra o atual governo repressivo. No entanto, as constantes lutas pelo poder têm sido repelidas com ações violentas, que agravam ainda mais a sobrevivência em solo venezuelano. Por isso, tem ocorrido o fenômeno social do grande contingente de pedidos de refúgios para o Brasil.

\section{A proteção brasileira dos Direitos Humanos aos Estrangeiros à luz dos Tratados Internacionais}

A partir dos aportes teóricos construídos e das constantes violações dos direitos humanos dos migrantes e refugiados, os mecanismos internacionais criaram tratados para regulamentar a 
proteção necessária aos direitos humanos de todos os indivíduos, sem distinção de nacionalidade. Dentro da seara global, o paradigma da cooperação entre os povos para a sobrevivência humana tem sido o elemento essencial para a ressignificação dos países de suas políticas de recebimento dos estrangeiros.

Com o contexto de final da II Guerra Mundial e a verificação da violência e dizimação de povos e comunidades, os países se reuniram e assinaram a Carta das Nações Unidas de 1945, que deu origem a Organização das Nações Unidas - ONU. Os direitos humanos ganham notoriedade dentro da seara internacional e passam a ser considerados basilares para a formação dos Estados a partir da Declaração Universal dos Direitos Humanos de 1948, tendo como garantia primordial a dignidade da pessoa humana e a efetividade dos direitos humanos essenciais à vida, como se verifica abaixo:

A Carta das Nações Unidas de 1945 consolida, assim, o movimento de internacionalização dos direitos humanos, a partir do consenso de Estados que elevam a promoção desses direitos a propósito e finalidade das Nações Unidas. Definitivamente, a relação de um Estado com seus nacionais passa a ser uma problemática internacional, objeto de instituições internacionais e do Direito Internacional. (PIOVESAN, 2016b, p. 189).

A partir dessas considerações, foram criados diversos tratados internacionais que buscam garantir os direitos fundamentais ao mínimo existencial aos indivíduos, fazendo com que os países signatários tenham como missão efetiva o respeito aos direitos humanos. Tais perspectivas passam a ser vislumbradas como institutos capazes de garantir a ajuda humanitária necessária para qualquer sujeito que busque abrigo em outro país. Vejamos os principais tratados históricos internacionais:

Os tratados de direitos humanos das Nações Unidas haveriam, ademais, de coexistir com outras convenções "gerais, a nível regional (a Convenção Européia de Direitos Humanos, de 1950; a Convenção Americana sobre Direitos Humanos, de 1969, subsequente à Declaração Americana sobre os Direitos e Deveres do Homem, de 1948, a qual, por seu turno, precedeu em alguns meses a Declaração Universal; a Carta Africana de Direitos Humanos e dos Povos, de 1981). Os instrumentos de direitos humanos, nos planos global e regional, haveriam de se complementar mutuamente, em vez de competirem uns com os outros. (TRINDADE, 2008, p. 2).

Em consideração a situação dos migrantes e, em especial dos refugiados, foi criado o Alto Comissariado das Nações Unidas para os Refugiados em 1950, com a Convenção de 1951, relativa ao Estatuto dos Refugiados e o Protocolo de 1967 em Genebra que alterou e ampliou as previsões anteriores. Na visão de Jubilut (2007), o Alto Comissariado das Nações Unidas para os Refugiados (ACNUR) é um órgão subsidiário da ONU, que é instaurado quando os tratados de proteção não são suficientes e passam a buscar soluções para a questão dos refugiados, estabelecendo o diálogo entre os atores internacionais. 
Ainda com o intuito de proteger a situação dos refugiados, a Convenção de 1951 e o Protocolo de 1967 estabeleceram as hipóteses e meios de inclusão e exclusão que devem ser observadas pelos países para o reconhecimento da situação de refugiado, tendo por base as referências externas que levaram ao deslocamento forçado.

Dentro do cenário das Américas, Trindade (2008, p. 105) destaca que os institutos de maior relevância dentro do sistema interamericano de proteção dos direitos humanos dos estrangeiros são: "a Declaração de Cartagena sobre Refugiados de 1984, a Declaração de São José sobre Refugiados e Pessoas Deslocadas, a Declaração e o Plano de Ação do México de 2004 para fortalecer a Proteção Internacional dos Refugiados na América Latina."

Tais institutos são instrumentalizados pela Convenção Americana de Direitos Humanos, tendo a Comissão Interamericana de Direitos Humanos como função principal de garantir a observância e a defesa dos direitos humanos no Continente Americano, de acordo com os artigos 41 e 44 da Convenção Americana de 1992.

Dentro do plano nacional brasileiro, percebe-se que o país ratificou os tratados internacionais de direitos humanos, aderindo aos pactos da Organização das Nações Unidas (ONU), da Organização dos Estados Americanos (OEA), da Convenção Americana de Direitos Humanos $(\mathrm{CADH})$, em 1992, e reconheceu a jurisdição obrigatória da Corte Interamericana de Direitos Humanos (CIDH) em 1998.

Em atenção pormenorizada à situação dos estrangeiros, segundo salienta Almeida (2000), a partir de 1997, o Brasil incorporou a Convenção sobre o Estatuto do Refugiado de 1951 e criou a Lei no 9.474 de 1997, que implementou o tratado internacional dos direitos humanos. Nas lições de Rezek (2016) tal inovação legislativa representou um marco no comprometimento do país para os refugiados.

Após isso, salienta Mazzuoli (2015) que outro grande marco legislativo nacional foi a criação do Estatuto do Estrangeiro pela Lei no 6.815 de 1980, que definiu a situação jurídica do estrangeiro no Brasil e criou o Conselho Nacional de Imigração. No entanto, a doutrina majoritária aponta para um caráter implícito de seleção do imigrante ideal, de adequação do estrangeiro ao interesse nacional e de tratamento dos que buscavam auxílio junto ao país como inimigos nacionais.

Já em 2017 foi criada a Lei n. 13.445/2017 - Lei de Migração, que revogou o estatuto do estrangeiro e permitiu a ruptura com a ideia do estrangeiro como figura ideal para ser aceito e retirou o caráter implícito de discriminação de refugiados, vistos antes como inimigos à segurança nacional. Essa lei busca, acima de tudo, a cooperação para o progresso da humanidade e a garantia dos direitos humanos, que estão estatuídos na Constituição da República Federativa do Brasil de 1988, como pertencentes a todos os indivíduos que estejam no país, sem distinção.

O texto da nova Lei de Migração estabeleceu novos princípios para o tratamento dos estrangeiros, rompendo com a visão criminalizante daquele que ingressava em território nacional. Ademais, a nova lei é reconhecida como um avanço no cenário internacional, uma vez que tem por base o cumprimento das organizações internacionais, considerando a necessidade de universalização 
dos direitos humanos, sem distinção ao estrangeiro. Tal propositura legal reforçou a importância de combater a discriminação, em especial a xenofobia, sendo instrumento para a adoção de políticas públicas de inclusão dos povos estrangeiros no solo brasileiro.

Em se tratando da situação dos refugiados em solo brasileiro, o Alto Comissariado das Nações Unidas para os Refugiados (ACNUR), órgão específico para tratar da questão dos refugiados, traz para si a responsabilidade de proteção do indivíduo por meio de política participativa e integralizada com o governo brasileiro. Nesse sentido, Piovesan (2016a) explica que os refugiados pedem a solicitação para a Polícia Federal e a decisão passa a ser de ordem do Comitê Nacional para Refugiados, que atua com vistas à proteção ampla do indivíduo, numa perspectiva humanitária.

No entanto, mesmo com toda a proteção humanitária dada aos estrangeiros e aos refugiados há, no Brasil, processos de invisibilização social, decorrentes da ruptura legislativa com a realidade prática vivenciada no país. O contexto social que ora se delineia na sociedade brasileira denota à exclusão e marginalização dos povos que buscam refúgio ou migram, de forma espontânea, para o país.

\section{0 processo de invisibilização social dos migrantes e refugiados e os conflitos migratórios na realidade brasileira}

Quando se analisa as transformações históricas das sociedades percebemos que as relações coletivas têm sido modificadas e reformuladas pelas características fluidas e frágeis. Tendo por base os estudos de Chambouleyron (2009) podemos perceber que os tempos contemporâneos refletem a ausência de preocupação com o convívio sólido e harmônico. As diversas faces da realidade pósmoderna puseram em evidência os interesses individuais como fundamentais para a satisfação do ser humano.

Dentro dessa conjuntura, os interesses da coletividade são colocados à margem da sociedade do consumo imediato e individualista. Por esse aspecto, nos remetemos aos ensinamentos de Bauman (2001) que afirma que a ausência de empatia e fraternidade nas relações sociais revela a fragilidade do direito à igualdade nos tempos líquidos modernos. O ser humano deixa de considerar, como fator principal do convívio coletivo, o respeito ao outro e aos direitos humanos a eles inerentes. Percebe-se que a identidade coletiva se tornou dispensável diante das relações virtuais e limitadas ao interesse próprio de cada cidadão.

Cada indivíduo passa a atuar dentro do cenário social como seres distintos e incapazes de refletirem à condição humana do próximo. Em atenção aos estudos de Sennet (1998) inferimos que a corrosão dos laços afetivos fez surgir um processo de retrocesso histórico das realidades democráticas. Tal retrocesso se perfaz quando vivenciamos um período de ascensão do Estado Democrático de Direito, com garantias e direitos humanos colocados como instrumentos basilares para norteamento de toda a ordem jurídica, mas, marcado pela inefetividade dos direitos normatizados, uma vez que a teoria não se amolda à realidade vivenciada em sociedade. 
A partir dessas ilações nos reportamos aos pensamentos filosóficos de Arendt (2010), que estabeleceu que o grande paradigma da era da pós-modernidade reside na espetacularização da condição humana efêmera e na neutralização dos sujeitos marginalizados. Os tempos contemporâneos trouxeram consigo o perigo de não efetividade da condição mais básica da vida humana, qual seja a pluralidade e dignidade humana. Em busca da realização dos interesses individuais, os cidadãos refletem o paradoxo da vida coletiva que não se identifica mais como plural.

Formadas por seres coletivos desprovidos de empatia e respeito aos direitos humanos uns dos outros, os conflitos sociais passam a ser acentuados pela competição da vida perfeita e espetacular, que Debord (2000) aponta como a sociedade do descarte. Aprendemos a descartar bens materiais inúteis e efêmeros, de prazeres momentâneos, e estendemos esse descarte para as relações humanas, na medida em que invisibilizamos os sujeitos que não se enquadram na vida perfeita da pós-modernidade.

Nesse panorama, Sennet (1998) afirma que a individualização dos interesses nos tornou uma sociedade do isolamento, que apresenta sua fragilidade na ineficiência de compreender o ser humano como um ser sociável. Sob esse aspecto, trazendo essa realidade para os processos migratórios brasileiros, observamos que as relações entre os estrangeiros e os nacionais são marcadas pelos efeitos dessa sociedade pós-moderna da fragilidade das relações.

Em consideração ao intenso fluxo migratório que o país tem recebido, ocasionados por diferentes causas que culminaram com o deslocamento dos povos por melhores condições de vida, temos observado a crescente resistência dos brasileiros em aceitar os migrantes e refugiados dentro do solo nacional. Revestidos por um discurso de insegurança política e ineficiência dos serviços públicos estatais, a maior parcela da população passou a considerar o estrangeiro como o inimigo do Estado e do próprio cidadão brasileiro.

Dentro desse cenário, o estrangeiro que migrou para o Brasil por situações de vulnerabilidade social no seu país de origem encontra dificuldades de aceitação dos brasileiros, que os enxergam como competidores do bem-estar social proporcionado aos locais. Nessa linha de intelecção, percebemos que os refugiados e migrantes tornam-se vulneráveis também dentro do solo brasileiro, colocados à margem da sociedade, como sujeitos que incomodam os interesses individuais dos povos nacionais.

Percebe-se, no entanto, que os conflitos migratórios estão correlacionados com os processos de neutralização social dos migrantes e refugiados, que são subjugados e considerados como indivíduos criminosos e violentos, sendo realocados para a condição de não pertencentes a essa sociedade, inimigos dos povos nacionais e ausentes de proteção de direitos humanos, mesmo com a proteção brasileira normatizada dos estrangeiros.

Sob essa ótica, com o intuito de compreender as origens dos conflitos migratórios, o Observatório das Migrações Internacionais - OBMigra realizou uma pesquisa qualitativa, composta por entrevistas aos estrangeiros e refugiados advindos da Venezuela, que tem sido palco de um fluxo intenso de deslocamentos populacionais devido às crises humanitárias vivenciadas pelo país decorrentes da instabilidade econômica e política. 
Percebeu-se que os dados obtidos na pesquisa do OBMigra vão de encontro ao discurso sensacionalista que figuram o estrangeiro que se refugia no país, como seres violentos, ligados à criminalidade e com déficit educacional. Na realidade, segundo o Alto Comissariado das Nações Unidas (2019), dos venezuelanos que entraram no Brasil até fevereiro de 2019, 96,2\% possuíam nível médio completo e 34,4\% tinham ensino superior ou nível de pós-graduação, contra 15,7\% da população brasileira, no mesmo período.

Em se tratando dos conflitos criminais envolvendo venezuelanos, o Alto Comissariado das Nações Unidas (2018) divulgou o número de ocorrências policiais envolvendo imigrantes até setembro de 2018. Destacou-se que apenas 11 casos de crimes policiais envolviam imigrantes e não se tratavam de delitos de maior potencial ofensivo.

É mister destacar que os conflitos migratórios são marcados pelo senso comum, que subjugam a figura do estrangeiro como inimigo da sociedade. Destarte, a resistência da população brasileira de partilhar o serviço público por insegurança de esgotamento dos serviços denota a necessidade de conscientização da população para resgatar o respeito aos direitos humanos a todos os indivíduos, sem distinção de origem, para que se possa efetivar a igualdade social e dirimir os conflitos resultantes dos preconceitos da sociedade.

\section{Justiça Restaurativa: instrumentos eficazes de transformação da consciência coletiva para o respeito aos direitos humanos dos refugiados e migrantes}

Os fenômenos migratórios são complexos e possuem causas variadas, que se desdobram na instabilidade política e socioeconômica dos indivíduos. Nesse prisma, em busca de condições dignas de sobrevivência, os fluxos de migrantes para outros territórios são recorrentes e ganharam notoriedade na sociedade contemporânea a partir das crises globais humanitárias. No entanto, após se deslocar para outro território, os imigrantes acabam se deparando, de forma elevada, com a hostilidade dos nascidos e residentes no país local.

Para os povos locais do país receptor, a presença, em massa, de imigrantes, por meio de uma visão rasa e xenófoba, ampliaria os problemas de inefetividade do Estado dos direitos sociais e geraria a insegurança no país. Diante dessa realidade, a aplicação dos métodos restaurativos será fundamental para a compreensão das causas da imigração, dando a oportunidade da superação dos conflitos culturais, a fim de alcançar a paz social entre os povos, tendo em vista o caráter de diálogo e cooperação que abaliza os meios de restauração.

Antes de compreender as formas de aplicação dos métodos restaurativos nos conflitos migratórios, faz-se necessário analisar as bases axiológicas de formação da Justiça Restaurativa no Brasil e o seu papel de reparação e composição dos danos. Sob a perspectiva de sua natureza, realizaremos uma pesquisa aplicada, com procedimentos técnicos bibliográficos e documentais acerca da Justiça Restaurativa, a fim de evidenciar a possibilidade de aplicação de seus métodos 
diante de cada contexto dos conflitos migratórios, como instrumento de mitigação do processo de invisibilidade social dada aos migrantes e refugiados para a garantia do cumprimento dos direitos humanos a todos os indivíduos.

Segundo Tourinho (2017), em um contexto alternativo das formas de resolução de conflitos por meio de processos jurídicos, a Justiça Restaurativa se apresenta como uma reformulação da concepção da justiça, trazendo à baila a composição dos danos e o empoderamento das partes como elemento essencial para se alcançar a efetiva justiça social. Trata-se da possibilidade de resolução de conflitos de maneira consensual e direta, sem necessidade de instauração de processo para que os métodos restaurativos alcancem resultados.

Nessa esteira, percebemos que a Justiça Restaurativa pode ser aplicada tanto na fase processual, como nas fases de execução penal e pré-processual. Na medida em que se reconhece as vivências restauradoras como meios de pacificação social, permite-se verificar que se tratam de modelos passíveis de atuação no cotidiano da sociedade, em situações fáticas informais e rotineiras, por meio da organização da comunidade, como exercício diário da cidadania.

Dentro desse contexto, as práticas restaurativas são formulações de composição de danos que transcende a concepção penal, sendo passível de aplicação para resolução de conflitos de todas as naturezas, com vistas à garantir a prevenção e conscientização social. Nas lições de Zehr (2018), por ser uma Justiça que se torna inovadora e, ao mesmo tempo, faz questionar as reais funções do Direito, em si, esta não se limita a um conceito fechado e hermético.

Em consonância a esse pensamento, Tourinho (2017) afirma que o caráter multifacetário da Justiça Restaurativa permite que esta se amplie e alcance novos caminhos de fazer justiça para se alcançar a paz social e a ordem jurídica. Mais do que um modelo de reprovação dos conflitos ocasionados, trata-se de um instrumento de transformação social, permitindo que as partes participem do momento de construção da composição dos danos, para que estas possam superar o evento traumático.

Nesse sentido, conforme salienta Sica (2007), a Justiça Restaurativa e seus modelos de aplicação podem ser utilizados não apenas em um contencioso penal, mas também nas resoluções de conflito extrajudiciais, permitindo a composição dos danos. Sendo assim, pode-se definir os objetivos e características da Justiça Restaurativa da seguinte forma:

A justiça restaurativa procura equilibrar o atendimento às necessidades das vítimas e da comunidade com a necessidade de reintegração do agressor à sociedade. Procura dar assistência à recuperação da vítima e permitir que todas as partes participem do processo de justiça de maneira produtiva. (BRAITHWAITE, 2002).

Desta feita, dentro do plano nacional, após o advento da Resolução n 225/2016 do Conselho Nacional de Justiça, os métodos restaurativos propõem a edificação de uma justiça pautada no diálogo e no respeito aos direitos fundamentais, com a participação, quando conveniente 
e possível, da comunidade de próximos, promovendo-se o empoderamento dos envolvidos e a pacificação social. Sobre a aplicação da Justiça Restaurativa no Brasil, vejamos:

Art. $1^{\circ}$. A Justiça Restaurativa constitui-se como um conjunto ordenado e sistêmico de princípios, métodos, técnicas e atividades próprias, que visa à conscientização sobre os fatores relacionais, institucionais e sociais motivadores de conflitos e violência, e por meio do qual os conflitos que geram dano, concreto ou abstrato, são solucionados de modo estruturado [...] (CONSELHO NACIONAL DE JUSTIÇA, 2016).

A partir da leitura detalhada da Resolução nº 225/2016, podemos inferir que a Justiça Restaurativa no Brasil ganha notoriedade como uma justiça penal de transformação e pacificação social, tendo por base a satisfação das necessidades de todos os envolvidos no conflito criminal e, permitindo a superação do evento traumático.

Segundo as lições de Pranis (2010, p. 255), "a fase processual da reparação é uma atuação interdisciplinar, que requer a ajuda conjunta de profissionais jurídicos com psicólogos para tentar trazer a solução para o fim das angústias de cada indivíduo envolvido no conflito." Dessume-se dos contornos teóricos ora delineados que, a reparação é um passo fundamental para se alcançar a efetividade da justiça criminal para todos os envolvidos.

A partir dessas considerações, a Justiça Restaurativa surge como uma proposta de resolução dos conflitos migratórios, com o intuito de desmistificar os estigmas enraizados no discurso ideológico da sociedade brasileira de exclusão e invisibilidade dos migrantes e refugiados. A partir dos dados relatados pelo Alto Comissariado das Nações Unidas (2018, 2019), percebeu-se que a falta de informação e de diálogo da comunidade local brasileira com os estrangeiros fez com que surgisse a associação pejorativa dos estrangeiros como inimigos da sociedade, sem escolaridade, violentos e criminosos.

No entanto, os dados das pesquisas evidenciaram que a taxa de escolaridade da população refugiada e migrante é maior do que a taxa da própria população local, revelando que a busca pelo refúgio não se deu como forma de fugir de atos criminosos, mas por situações externas de extrema repressão dos direitos humanos.

Por esse aspecto, a Justiça Restaurativa e as suas formas de aplicação serão essenciais para permitir a introdução do diálogo entre os grupos nacionais e estrangeiros, no sentido de tocar a origem e causa dos conflitos culturais entre imigrantes e locais, possibilitando o amadurecimento pessoal da população do país acerca da presença dos refugiados e migrantes, com o intuito de viabilizar a realização de direitos que garantam a existência digna.

Sobre aplicação da Justiça Restaurativa envolvendo relações comunitárias pode-se destacar umas das considerações da Resolução nº 225/2016:

CONSIDERANDO que, diante da complexidade dos fenômenos conflito e violência, devem ser considerados, não só os aspectos relacionais individuais, 
mas também, os comunitários, institucionais e sociais que contribuem para seu surgimento, estabelecendo-se fluxos e procedimentos que cuidem dessas dimensões e promovam mudanças de paradigmas, bem como, provendo-se espaços apropriados e adequados; (CONSELHO NACIONAL DE JUSTIÇA, 2016).

A pesquisa proposta se direciona à análise da aplicabilidade dos métodos restaurativos nos conflitos presentes nos fenômenos migratórios. Nesse espaço teórico, observamos que a população local fundamenta o seu preconceito por meio do senso comum, que parte de inverdades a respeito do imigrante.

Com vistas à desconstrução dos discursos de ódio ao imigrante, a Justiça Restaurativa dará a oportunidade do diálogo, trazendo a reflexão dos residentes locais a se colocarem na posição dos imigrantes. Nesse sentido, embasado nas premissas do respeito e da empatia, será dada a oportunidade para a superação do choque cultural, a partir da perspectiva de consideração do estrangeiro como ser humano, dotado de direitos essenciais para sua existência.

A Justiça Restaurativa está pautada na resolução dos conflitos por meio da mitigação do seu efeito estigmatizador e excludente, para que, por meio do diálogo e do respeito aos direitos fundamentais, com a participação da comunidade de próximos, seja possível a descoberta de uma solução que proporcione o empoderamento dos envolvidos e a pacificação social.

Diante do exposto, sem a pretensão de esgotar as possibilidades de aplicação da Justiça Restaurativa, tendo em vista o seu caráter multifacetário, faremos um recorte bibliográfico, por meio dos cultores da área das principais formas de aplicação dos modelos restaurativos que podem servir de base para a resolução dos conflitos migratórios e garantir a conscientização da população para o respeito aos direitos humanos dos estrangeiros.

A partir das ilações de Dignan e Marsh (2003), há três procedimentos primordiais de aplicação da Justiça Restaurativa que permitem a associação dos elementos essenciais restaurativos, quais sejam o empoderamento das partes, a participação dos envolvidos, a reparação dos danos e a superação do evento traumático, tendo como consequência, que se espera de forma paulatina, a conscientização da população.

Dentro do plano nacional, observamos na Resolução no 225/2016 que há também um leque aberto de definição de modelos restaurativos definindo a prática restaurativa como a forma diferenciada de tratar os conflitos, com enfoque restaurativo. Vejamos:

$\int 2^{\circ} \mathrm{A}$ aplicação de procedimento restaurativo pode ocorrer de forma alternativa ou concorrente com o processo convencional, devendo suas implicações ser consideradas, caso a caso, à luz do correspondente sistema processual e objetivando sempre as melhores soluções para as partes envolvidas e a comunidade.

Art. $2^{\circ}$ São princípios que orientam a Justiça Restaurativa: a corresponsabilidade, a reparação dos danos, o atendimento às necessidades de todos os envolvidos, a informalidade, a voluntariedade, a imparcialidade, a participação, o empoderamento, a consensualidade, a confidencialidade, a celeridade e a urbanidade. (CONSELHO NACIONAL DE JUSTIÇA, 2016). 
Para fins desse artigo, optamos por estudar três procedimentos que consideramos basilares para a aplicação da Justiça Restaurativa, quais são: as conferências, os círculos e a mediação. Tais modelos restaurativos, segundo Pallamolla (2009) trazem, em seu bojo, a responsabilização, a prevenção social e as possibilidades de empoderamento das partes para superação do evento traumático. Em uma análise pormenorizada dos modelos trazidos por Dignan e Marsh (2003), percebemos que as conferências restaurativas constituem-se em encontros entre as partes, com o intuito de realizar acordos de reparação e composição dos danos, de maneira dialogada e de acordo com a vontade das partes.

Nessa mesma linha de raciocínio, Ceretti, Di Ciò e Mannozzi (2001, p. 89) informam que o International Scientific and Professional Advisory Council of the United Nations Crime Prevention and Criminal Justice Programme - ISPAC - "considera as conferências como mediações ampliadas, na medida em que possibilitam a participação de membros da comunidade, envolvidos diretamente no conflito, no sentido de auxiliarem na solução do problema."

Dentro desse prisma, as conferências possuem um conceito amplificativo, sendo possível que seus métodos sejam, também, realizados para atingir a comunidade próxima, passando a atuar como instrumento de conscientização social. Esses grupos ou redes, como pontuam Raye e Roberts (2007, p. 87), "podem ser formados por familiares e pessoas que servirão como apoio da vítima e do infrator, como amigos, professores, por exemplo, ao que denominam de community of care."

Com efeito, quando se analisa as possibilidades de aplicação dos modelos restaurativos dentro da resolução dos conflitos migratórios, as conferências passam a ser elementos essenciais para iniciar o diálogo entre a população local e os estrangeiros. A partir das construções de conferências entre as partes, com a apresentação das suas narrativas e a exposição da realidade dos migrantes e refugiados, pode-se vislumbrar o primeiro passo para o processo de ruptura com os estigmas do preconceito ligado à xenofobia.

Espera-se que o desenvolvimento das conferências permita debates da comunidade com profissionais da área jurídica, bem como representantes do Alto Comissariado das Nações Unidas (2019) para explicar os aportes jurídicos legais que regulamentam os direitos humanos para os refugiados e migrantes, estabelecendo como premissa básica, o respeito dos povos e a busca pela igualdade. Ademais, por meio dessas conferências podem ser delineadas as estatísticas evidenciadas nas pesquisas da OBMigra (SIMÕES, 2017), a fim de demonstrar que a discriminação feita aos refugiados e migrantes são promovidas pelo sensacionalismo midiático, desprovidos de verdade e de cunho científico.

O segundo modelo restaurativo a ser analisado são os círculos restaurativos, que podem ser formulados com diversas especificidades, a fim de atender a necessidade do caso concreto. Carlucci (2004) afirma que os círculos podem ser utilizados de forma parcial, com encontros promovidos somente entre a população estrangeira que adentra o país, garantindo informações de auxílio 
humanitário, asilo político, legalização da entrada. Mas também podem ser utilizados círculos totais, com encontros participativos com a população nativa, permitindo a aproximação entre eles.

Por outro lado, os círculos também podem ser desenvolvidos no âmbito da própria comunidade, em vivências restauradoras singulares e comunitárias, contando com a ampla participação de todos os envolvidos. Desse modo, Tourinho (2017) chama a atenção para a possibilidade de reaproximação das partes, a partir do início do processo de conscientização que pode ser desenvolvido nesse modelo restaurativo, tendo em vista que as etapas progressivas de encontros permitem a identificação do problema, a sensibilização das partes e a construção dialogada dos resultados.

Ainda destacamos a mediação como processo restaurativo válido para a resolução dos conflitos migratórios, em razão de ser um modelo que prima pela comunicação entre as partes, por meio do empoderamento das partes para a busca por uma solução. É válido ressaltar que essa autonomia dada às partes é fundamental para que os envolvidos se sintam sensibilizados pelo conflito e possam compreender as causas que deram ensejo ao evento.

A mediação permite, acima de tudo, a abertura de diálogos embasados pelos princípios do respeito, da não dominação das partes, do equilíbrio entre as decisões e, em especial, do resgate às técnicas de comunicação não violenta. Nas lições de Marshall, Boyack e Bowen (2015), quando se utiliza as técnicas de uma comunicação pautada no respeito e na busca da convivência equilibrada, permite-se se desvencilhar dos preconceitos enraizados nos discursos sociais, dando espaço para a valorização da palavra do próximo e do sentimento de igualdade entre os povos.

Para Cruz Parra (2013, p. 130), a mediação pode ser concebida como "um procedimento dentro do processo, no qual as partes, ajudados por um mediador oficial podem decidir o conteúdo do acordo de reparação cujo cumprimento efetivo paralisaria o progresso da ação."

Nessa mesma linha de raciocínio, Sica (2007, p. 51) afirma que a mediação, com base no "instrumento de escuta das emoções, permite a revelação e o reconhecimento pleno das necessidades e dos valores das pessoas em conflito e, portanto, o incremento das possibilidades que cheguem a um acordo estável e duradouro." Tal ilação pode ser visualizada dentro dos conflitos migratórios como o caminho para a conscientização dos cidadãos para o respeito ao migrante e aos refugiados como sujeitos de direitos, destacando a importância de dar voz aos atores que são silenciados dentro da sociedade, para combater os preconceitos sociais e fortalecer os laços humanos dentro das relações contemporâneas.

\section{Considerações finais}

A criação da Declaração das Nações Unidas em 1945 reconheceu, pela primeira vez, de maneira formal, a necessidade de um panorama jurídico de proteção dos direitos humanos, sendo estabelecida como função dos Estados a cooperação para a efetividade do direito à paz e redução 
dos conflitos entre os povos, bem como o estabelecimento de mecanismos para garantir a todos os indivíduos as condições mínimas de existência.

Respaldados pelo caráter transnacional, os direitos essenciais à vida são colocados como valores supremos a serem obedecidos pelas ordens jurídicas dos países, que devem buscar abrigar e recepcionar os indivíduos em uma missão de humanidade. No entanto, o que se percebe é que os migrantes e refugiados, que já foram suprimidos no seu país local, passam a serem ameaçados nos países receptores, em razão dos conflitos migratórios com os povos nacionais.

Dentro dessa conjuntura, a Justiça Restaurativa surge como um modelo de solução dos conflitos, com vistas à pacificação social, buscando intermediar os conflitos migratórios e criar a conscientização da população do país local para o acolhimento dos estrangeiros, livre de preconceito e estigmatização social.

Cumpre destacar que os modelos restaurativos, pautados pelos ideais de justiça, do diálogo e do respeito ao próximo são revestidos de instrumentos eficazes para atuação em processos préconflitos, bem como pós-conflitos. Essa modulação sistêmica da Justiça Restaurativa permite que esta seja aplicada não apenas como instituto de responsabilidade penal, mas também como meio de conscientização para o reconhecimento dos discursos preconceituosos e a sua, consequente, erradicação dentro da sociedade.

Nesta esteira, a Justiça Restaurativa se consubstancia como meio de alcance da efetividade da justiça social, garantindo o cumprimento dos direitos humanos a todos os povos, sem discriminação de credo, territorialidade, gênero, religião e nação. Abre-se espaço para a reflexão da sociedade sobre os preconceitos enraizados, simbolicamente, nas ações cotidianas, que marginalizam povos das garantias constitucionais.

Os métodos restaurativos atuam como uma nova lente que permite desmistificar os processos de invisibilização, tornando visível quem antes era posto como excluído e revelando as realidades plurais dos indivíduos. Nesse sentido, a Justiça Restaurativa permite restaurar a comunicação entre os povos locais e estrangeiros, a fim de dirimir os conflitos migratórios.

\section{REFERÊNCIAS}

ALTO COMISSARIADO DAS NAÇÕES UNIDAS. ACNUR intensifica sua resposta diante do aumento das solicitações de refúgio de venezuelanos. [S. l.: s. n.], 2017. Disponível em: http://www.acnur.org/ portugues/noticias/noticia/acnurintensifica-sua-resposta-diante-do-aumento-das-solicitacoes-de-refugio-de-venezuelanos/. Acesso em: 10 jul. 2019.

ALTO COMISSARIADO DAS NAÇÕES UNIDAS. Perfil Socioeconômico dos refugiados no Brasil. [S. l.: s.n.], 2019. Acesso em: http://www.acnur.org/portugues/noticias/noticia/. Acesso em: 19 jun. 2019. 
ANDRADE, José H. F. de. Derecho de los Refugiados en América Latina: reflexiones sobre su futuro. In: NAMIHAS, Sandra (coord.). Derecho internacional de los refugiados. Lima: Pontificia Universidad Católica del Perú, 2001. p. 92-107.

ARENDT, Hannah. A condição humana. 11. ed. Tradução: Roberto Raposo. Rio de Janeiro: Forense Universitária, 2010.

BAUMAN, Zygmunt. Modernidade líquida. Tradução: Plínio Dentzien. Rio de Janeiro: Zahar, 2001.

BRAITHWAITE, John. Restorative justice and responsive regulation. New York: Oxford University Press, 2002.

BRASIL. Constituição. República Federativa do Brasil de 1988. Brasília, DF: Senado Federal, 5 out. 1988.

CERETTI, Adolfo; DI CIÒ, Francesca; MANNOZZI, Grazia. Giustizia riparativa e mediazione penale: esperienze e pratiche a confronto. In: SCAPARRO, Fulvio. Il coraggio di mediare. Milano: Guerini e Associati, 2001.

CHAMBOULEYRON, Ingrid Cyfer. A tensão entre modernidade e pós-modernidade na crítica à exclusão no feminismo. 2009. Tese (Doutorado em Ciência Política) - Faculdade de Filosofia, Letras e Ciências Humanas, Universidade de São Paulo, São Paulo, 2009.

CONSELHO NACIONAL DE JUSTIÇA. Resolução n. 225, de 12 de julho de 2016. Brasília, DF: CNJ, 2016. Disponível em: http://www.cnj.jus.br/busca-atos-adm?documento=1241. Acesso em: 25 fev. de 2019.

CORREIA, Theresa R. C. Corte Interamericana de Direitos Humanos: repercussão jurídica das opiniões consultivas. Curitiba: Juruá Editora, 2008.

CRUZ PARRA, Juan Antonio. La mediación penal: problemática y soluciones. Granada: Belicena, 2013 .

DEBORD, Guy. Sociedade do espetáculo. Rio de Janeiro: Contraponto, 2000.

DEVOTO, Fernando. La inmigración de ultramar. In: TORRADO, Suzana (ed.). Población y Bienestar en Argentina del Primero al Segundo Centenario. Una historia social del siglo XX. Buenos Aires: Edhasa, 2007.

DIGNAN, Jim; MARSH, Peter. Restorative justice and family group conferences in England: current state and future prospects. In: MORRIS, Alisson; MAXWELL, Gabrielle. Restorative justice for juveniles - conferencing, mediation and circles. Portland: Hart Publishing, 2003.

ELIE, Jerome. Histories of refugees and forced migration studies. In: OASMIYEH, Elena F. et al. The Oxford handbook of refugee and forced migration studies. Oxford University Press, 2014.

HORA, Roy. Historia económica de la Argentina en el siglo XIX. Buenos Aires: Siglo Veintiuno Editores, 2010 .

JUBILUT, Liliana Lyra. O Direito Internacional dos refugiados e sua aplicação no ordenamento jurídico brasileiro. São Paulo: Ed. Método, 2007. 
KEMELMAJER DE CARLUCCI, Aída. Justicia restaurativa: posible respuesta para el delito cometido por persona menores de edad. 4. ed. Santa Fe: Rubinzal Culzoni, 2004.

KLEIN, Herbert S. Migração Internacional na história das Américas. In: FAUSTO, Boris. (org.). Fazer a América - A imigração em massa para a América Latina. 2. ed. São Paulo: EDUSP, 2000.

LANZA, Líria Maria Bettiol; SANTOS, Amanda de Barros; RODRIGUES, Júlia Ramalho. Imigração, território e as políticas de seguridade social. Argumentum, v. 8, n. 3, p. 54-66, set./dez. 2016.

MARSHALL, Chris; BOYACK, Jim; BOWEN, Helen. Como a justiça restaurativa assegura a boa prática: uma abordagem baseada em valores. In: PINTO, Renato Sócrates Gomes; SLAKMON, Catherine; DE VITTO, Renato Campos. (org.). Justiça Restaurativa. Brasília, DF: Ministério da Justiça e PNUD, 2005.

MAZZUOLI, Valério. Curso de Direitos Humanos. 2. ed. rev., atual e ampl. São Paulo: Método, 2015.

MURILLO, Juan Carlos. A proteção internacional dos refugiados na América Latina e o tratamento dos fluxos migratórios mistos. Caderno de Debates Refúgio, Migrações e Cidadania, v. 3, n. 3, 2008.

OBREGÓN, Marcelo Fernando Quiroga. Venezuela em crise: o que mudou com Maduro? Revista Derecho y Cambio Social, 2018. Disponível em: https://www.derechoycambiosocial.com/revista052/ VENEZUELA_EM_CRISE//. Acesso em: 20 jun. 2019.

SIMÕES, Gustavo da Frota (org.). Perfil sociodemográfico e laboral da imigração venezuelana no Brasil. Curitiba: CRV, 2017. ORGANIZAÇÃO INTERNACIONAL PARA AS MIGRAÇÕES. Glossário sobre migração. Direito Internacional sobre Migração, n. 22. Genebra: OIM, 2009.

PALLAMOLLA, Raffaella da Porciuncula. Justiça restaurativa: da teoria à prática. São Paulo: IBCCrim, 2009.

PIOVESAN, Flávia. A Constituição brasileira de 1988 e os tratados internacionais de proteção aos direitos humanos. EOS Revista Jurídica da Faculdade de Direito, v. 2, n. 1, a. II, 2016a. Disponível em: http://www.vestibulardombosco.com.br/faculdade/revista_direito/3edicao/Artigo\%203.pdf. Acesso em: 12 fev. 2017.

PIOVESAN, Flávia. Direitos Humanos e o Direito Constitucional Internacional. 15. ed. São Paulo: Saraiva, 2016b. v. 15.

PRANIS, Kay. Processos circulares. São Paulo: Palas Athena, 2010.

PURDIN, Susan; MCGINN, Therese. Forced migration learning module: definitions. Columbia University: Mailman school of public health, 2010. Disponível em: http://www.columbia.edu/itc/hs/ pubhealth/modules/forcedMigration/definitions.html. Acesso em: 10 abr. 2019.

RAPOPORT, Mario. História económica, política y social de la Argentina, 1880-2000. Buenos Aires: Editorial Macchi, 2000.

RAYE, Barbara E.; ROBERTS, Ann Warner. Restorative processes. In: JOHNSTONE, Garry; VAN NESS, Daniel W. (ed.). Handbook of Restorative Justice. Cullompton, UK: Portland, USA: Willan Publishing, 2007. 
REZEK, José Francisco. Direito Internacional Público. 16. ed. São Paulo: Saraiva, 2016.

RODRÍGUEZ, Pedro Garrido. Inmigración y diversidad cultural en España. Un análisis histórico desde la perspectiva de los derechos humanos. Salamanca: Ediciones Universidad de Salamanca, 2012.

RODRÍGUEZ, Pedro Garrido. Inmigración y diversidad cultural en España. Su gestión desde la bonanza económica a la crisis. Madrid: Editorial Fundamentos, 2014.

SANCHEZ-ALONSO, Blanca. The other Europeans: immigration into latinamerica and the international labour market (1870-1930). Revista de Historia Económica/Journal of Iberian and Latin American Economic History, v. 25, n. 3, p. 395-426, 2007.

SENNETT, Richard. The corrosion of character: the personal consequences of work in the new capitalism. New York: W.W. Norton \& Co., 1998.

SICA, Leonardo. Justiça restaurativa e mediação penal: o novo modelo de justiça criminal e de gestão do crime. Rio de Janeiro: Lumen Juris, 2007.

SILVA, Paulo Henrique. Colômbia, migração internacional e política pública: o caso do programa Colômbia nos Une. Revista Conjuntura Autral, v. 4, n. 19, 2013.

SIMEON, James C. (ed.). The UNHCR and the Supervision of International Refugee Law. Cambridge: Cambridge University Press, 2013.

TOALDO, Mattia. Migrations through and from Libya: a Mediterranean challenge. IAI Working Papers, v. 15, 14 maio 2015.

TOURINHO, Luciano de Oliveira Souza. Justiça restaurativa e crimes culposos: contributo à construção de um novo paradigma jurídico-penal no estado constitucional de direito. Rio de Janeiro: Editora Lumen Juris, 2017.

TRINDADE, Cançado. Deslocados e a proteção dos migrantes na legislação internacional dos Direitos Humanos. Caderno de Debates Refúgio, Migrações e Cidadania, v. 3, n. 3, 2008.

ZEHR, Howard. Trocando as lentes: justiça restaurativa para o nosso tempo. 25. ed. Tradução: Tônia Van Acker. São Paulo: Palas Athena 2018. 
